\title{
ABA Based Intervention Implemented by a Mother of a Child with ASD
}

\author{
Migen Sulaj \\ European University of Tirana \\ Tirana, Albania
}

\begin{abstract}
Over the past 15 years there has been a dramatic increase in the incidence of autism. In 2014 the American Autism and Developmental Disabilities Monitoring Network reported estimated prevalence rates for Autism Spectrum Disorder (ASD) to be 1 in 68. At the same time, the number of professionals qualified to coordinate effective behavioral interventions has been limited and often prohibitively expensive. Several recent studies that include randomized trials have shown very promising results for involving parents of very young children with autism to integrate evidence-based strategies into daily routines with positive effects on core symptoms of the disorder. The present article shows that additional to staff treatment outcomes, positive treatment outcomes provided by parent involved in therapy are possible. The purpose of this case study article is to promote parent involvement in early intervention programs for children with autism. The objective is to open a new discussion on potential ways for better treatment outcomes hoping to propose a more economic model for a poor country like Albania.
\end{abstract}

Keywords: Autism Spectrum Disorders, mother intervention, outcomes

\section{Introduction}

The cause of the increasing number of children with autism is not yet known (Keenan, Dillenburger, 2014). Children with autism are considered disabled under the WHO definition for People with Disabilities. In Albania, according to the National Strategy for People with Disability, the number of people with mental, physical and senses disability is: Total 35547, Urban Areas 15166 and Rural Areas 20381. There is no evidence published about the number or prevalence of children with ASD in Albania. The small numbers the few autism centers existing in Albania might offer are not representative to all population. A national survey to estimate the prevalence of ASD hasn't been developed yet. We can assume however that the rate of children with autism in Albania is the same with that of other countries.

Although autism is a life span condition, since the 1960's many approaches and methods of intervention have been proven to be successful in treatment of autism (Deisinger, 2011). Much information about various intervention methods focusing on behavior modification for individuals with autism currently exists, however, professionals agree that parent involvement is crucial for the success of those interventions (Lai, Lombardo, \& Baron-Cohen, 2014; Beurkens, Hobson \&Hobson, 2013; Solomon \& Chung, 2012; Benson \& Carlof, 2008). Though the cause, the prevalence, and intervention methods of autism are widely researched, this author believes that more focus should be drawn to parental involvement, and how to support parents in their involvement.

In addition to trained therapists, this article basically proposes the parent involvement in early intervention programs for children with autism. Parent involvement is a complex process that requires consideration of the basic issue of parenting a child with autism. In recent years, a number of studies have begun to document the experiences of families caring for a child with autism. For example, Cashin (2004) conducted a phenomenology study involving nine parents of ASD children. This study identified several other themes in the data, indicating that parents experience less spontaneity, decreased social contact, fewer material things, and less time to pursue their own individual interests. However, positive experiences were also reported. For example, parents described rare moments when they truly connected with their child, and they noted tremendous personal growth in patience. Parent coping and stress levels experienced by parents of children with autism has been addressed by a number of quantitative studies. Much of the literature suggests that mothers and fathers of children with autism report significantly more stress than do parents of children without disabilities or parents of children with other disabilities, including chronic illnesses (Hastings, Kovshoff, Ward, Espinosa, Brown, \& Remington, 2005; Gray, 2002; Hastings \& Beck, 2004). Hastings and Beck (2004) also noted that when interventions result in children's language acquisition and in the reduction of problem behaviors, parents experience a greater sense of well-being and a reduction in 
reported stress levels. Interestingly, on the side of coping, Singh and colleagues (2006) suggested that stress levels can be reduced by teaching parents how to handle problem behaviors, including aggression. Some researchers have suggested that children perform best when their families acquire skills and knowledge along with the confidence to apply that knowledge (Dunlap \& Fox, 1999; Kuhn \& Carter, 2006).

\section{Method}

The article summarizes the results of a case study on the staff and parent involvement in autism treatment of one child female aged 4 years 2 months at the time of this study. The child had been diagnosed with ASD. She was attending the kindergarten but the outcome was just the girl being present in the setting. She was not benefiting neither educational nor other kind of service. The girl started to receive behavioral intervention in clinic setting. The system employs the technologies of Applied Behavior Analysis and Verbal Behavior to teach small, measure units of behavior and language systematically. After a period of 6 months of behavioral intervention in clinic setting, the clinic staff proposed to the mother of the child to be involved in the treatment. The mother would be involved in Early Intensive Behavior Treatment and in Problem Behaviors.Additionally parent involvement (mother) in clinic (45 min) and in home setting (45 min) was introduced than, targeting the replication and generalization of the above.

The girl had been integrated into mainstream school (kindergarten) for duration of time that is 16 months. The Albanian schools have on average 30:1 pupil: teacher ratio and implement the conventional Albanian mainstream curriculum. The girl receives full - time assistance from the aide who replicates the therapy program of the center and integrates it with school program. She continues to get clinical treatment of $7,5 \mathrm{~h}$ per week and additional parent intervention both in clinic and home setting.

\subsection{Data collection}

Data was collected during interventions performed by both clinic staff and the mother of the child. Target goals were the same for the staff and parent involved in the treatment. The goals were seen divided in two domains: first domain was acquisition of language and academic skills, self -help skills, social and play skills, class instruction and group instruction and first/then rule. These domain targets were tracked on monthly basis over 6 trials per goal per one hour session. The trials results were marked on every day basis as independent or prompted with type of prompt used being designated. The final data collection was plotted using a graph tracking multiple data points utilizing the discrete trial data training.

Language acquisition starting from vocal imitation, receptive and expressive level, requesting and intraverbals, following the commands, academic skills like writing and math, social rules and play skills, class and group instruction, yes/no and first/then rule - all were then plotted on two graphs as to percentage of successful trials per data tracking session. Graph 1 and 2 represent the staff and mother's intervention results in the first domain.

The second domain was Functional Behavior. ABC data collection form was used to track functional behaviors on monthly basis over the number of nonfunctional behaviors demonstrated per one session. Graph 3 and 4 on this other domain will be presenting the results of intervention implemented by the staff and the mother of the child.

\section{Presenting problems}

The case is represented by a child (girl) with autism and her mother who came in clinic to help her child. The child received $A B A$ at 1 year and 10 months. At the time of first assessment the girl was not attending any crèches or any state institution. She was not verbal, no imitation skills were present, she wouldn't turn when calling her name, she had no interest for toys of her age, no pointing, and no presence of receptive level. Stereotypes like moving around, emitting wired voices, movements of hands and goofy walking were present. She had no self-help skills, the play was immature and little imaginative play was present. Challenging and non functional behaviors at apparently no reason were present as well. The mother of the child was very interested to learn as much as possible on how to acquire the necessity skills to better help her child with the intervention. During the first sixth months of the clinic based intervention, the mother was present in every therapy hour. A common decision taken by the clinic staff and the mother of the child on initiating additional therapy hours 
carried by the mother under close supervision of the clinic was very natural at this stage. Therapeutic goal, data recording and results tracking were the same for both staff and parent.

Therapeutic Goal was to increase skills in imitation, language, play and socialization, academic skills while decreasing challenging behaviors.

The graphs below presents the results of interventions implemented by the staff and by the mother. Graph 3 and 4 on nonfunctional behaviors presents the reduction of these behaviors on monthly basis due to staff and parent implementation. The data was tracked on daily basis and then graphed for the 8 months of duration.
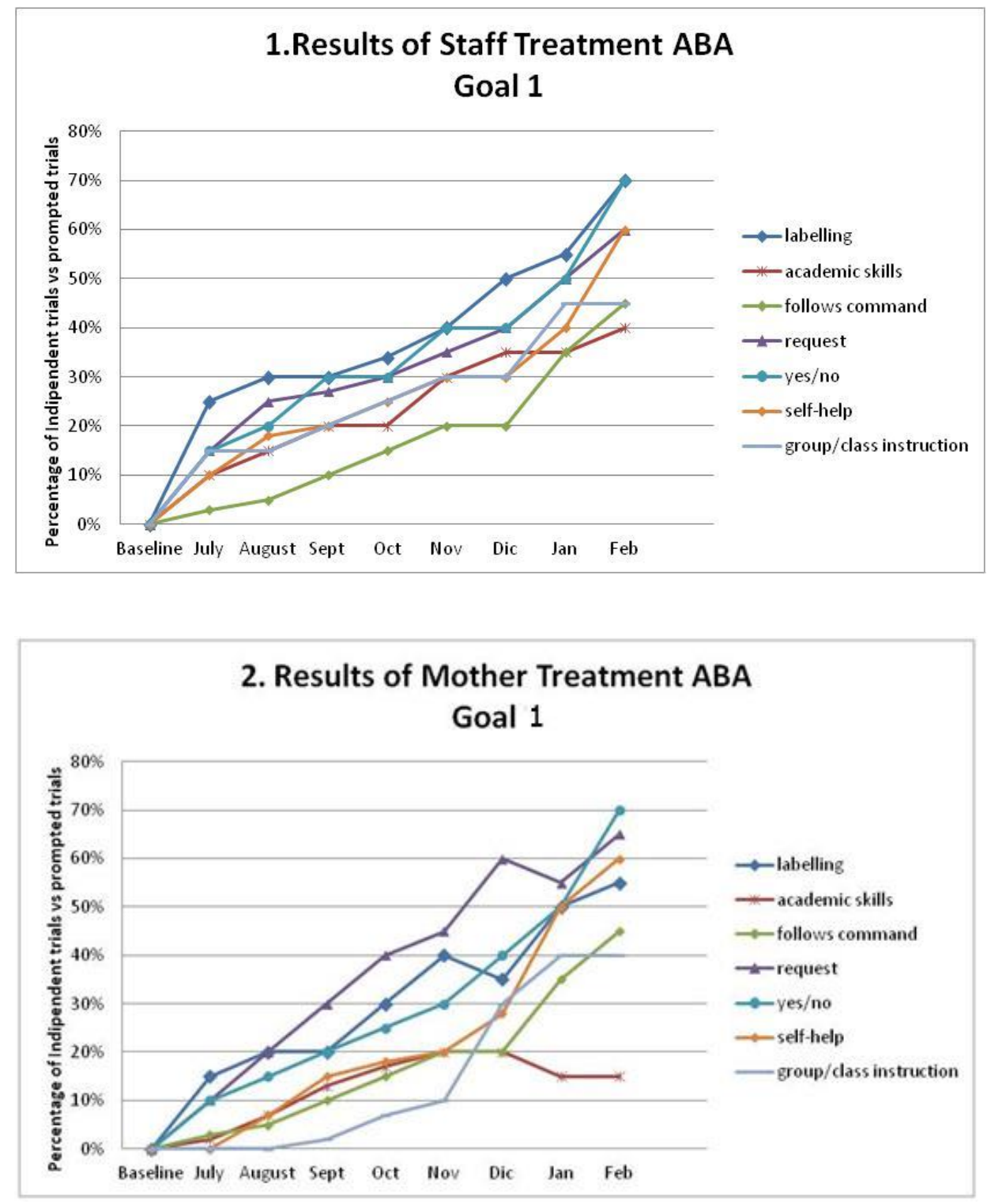

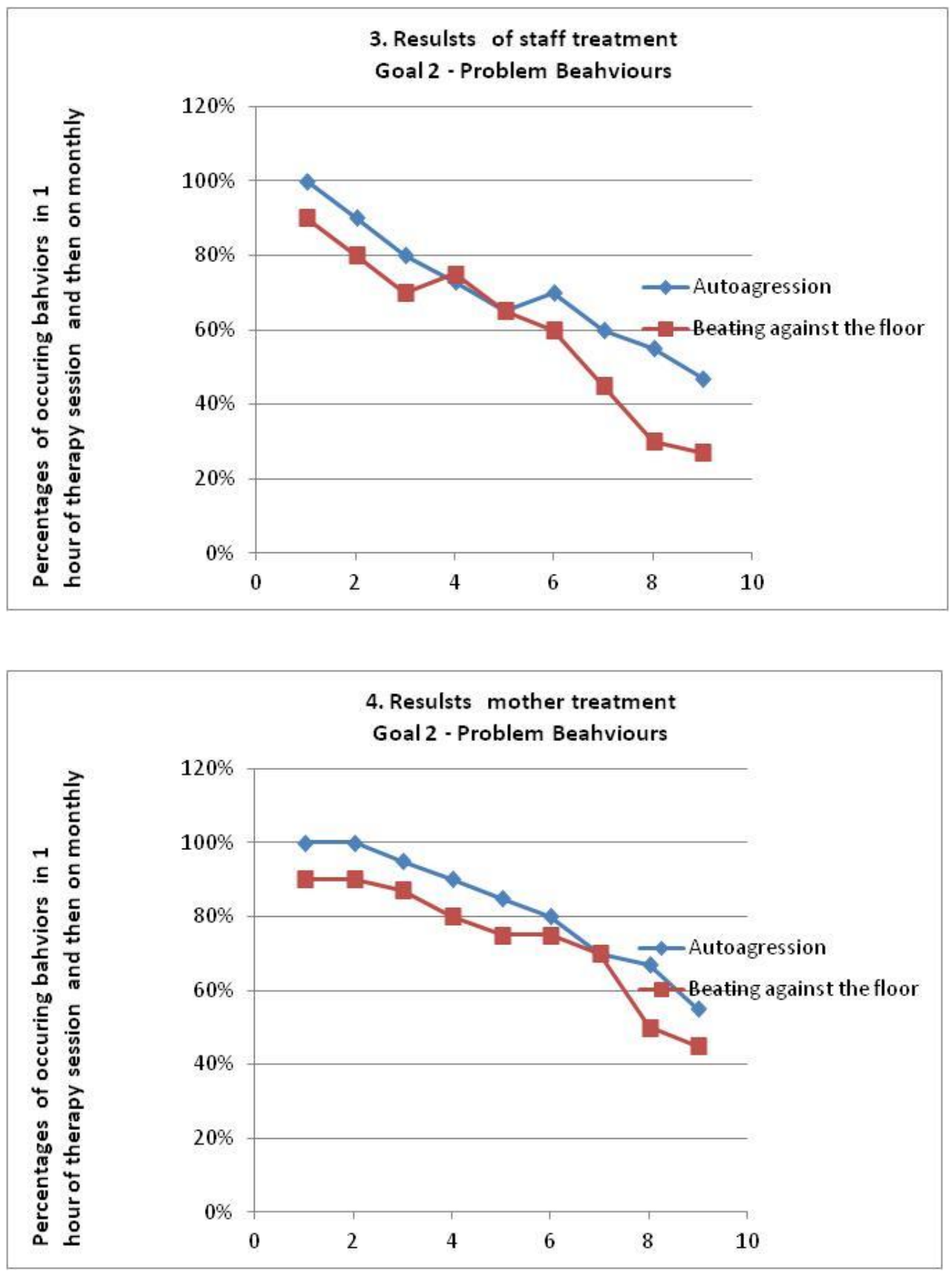


\section{Summary of changes}

The child acquisition of new skills and reduction of problem behaviors will be seen as a result of treatment implemented by clinic staff and the mother of the child as well. The child progress was assessed 8 months after attending kindergarten. The data collected on monthly basis using the Catalyst Data Collection Platform was utilized to determine the amount of progress toward goals 1 and 2.There was one aide who assisted the girl in the kindergarten setting. The teachers were very surprised. They stated that the little girl was much more compliant towards group and class instruction, she was showing less aggression or problem behaviors, her language level was impressive if compared with 7 months ago and that she would demonstrate academic abilities like reading, writing and math skills.

Parents noticed a decrease in problem behaviors, a decrease in self-harming behaviors, an increase of language acquisition and toileting skills achieved.

Therapists noticed improvement in imitation skills, language acquisition increased at level of three words statements and simple intraverbals, increased requests, almost no signs of self-injury, increased academic skills toilet training achieved at $100 \%$.

Graphs show that the progress scored during the mother intervention is somewhat lower than the progress scored by the therapists; however, the difference between the two actors is encouraging.

\section{Proposal of parent involvement in Early Intensive Behavior Treatment and Problem Behaviors in children with ASD}

Research on parent training in the field of ASD has indicated promising outcomes. There is a long tradition of parent training in the ASD literature, but it has not reached the sophistication level of treatment packages seen for typically developing children with compliance problems. Determining the best package methods for given ASD, and ASD severity, as well as modifications to programs based on age, is in order. Early intensive behavioral intervention packages often include a parenting component. This approach is significant and important since getting parents involved in these treatments as early as possible is advisable.

The bottom line of this article is to improve the lives of children and families living with autism through promoting additional treatment produced by the parents. In this case study, no specific training was designed nor implemented by the mother of the child except for learning through hands-on techniques. The tracked changes suggest that positive outcomes related to acquisition of new skills are possible even though intervention is offered by the mother of the child. Additionally, helping the mother of the child to learn behavioral techniques for teaching positive skills (such as language) and for reducing problem behaviors (such as aggression) is likely to have the most direct positive influence on the quality of life for families living with autism. The mother of the child confirms more serenity and hope perceived and felt in the family of the child.

Dillenburger, Keenan, Gallager, and McElhinney (2002) suggest that empowering parents is central to ABA treatment success. They note that parents can and should be trained to become their own child's therapist. By learning both content and hands-on techniques, parents are often able to take back some control over their family life. This case study is a small scale confirmation of the above suggestion.

\section{Reference}

[1] M. Keenan, K. Dillenburger, "Autism and ABA: The Gulf Between North America and Europe", Review Journal of Autism and Developmental Disorders @ Springer Science Business Media New York, 2014.

[2] Deisinger, J. (2011). Chapter 10 History of autism spectrum disorders, in Anthony F. Rotatori, Festus E. Obiakor, Jeffrey P. Bakken (ed.) History of Special Education (Advances in Special Education, Volume 21)Emerald Group Publishing Limited, pp.237 - 267doi: 10.1108/S0270

[3] 4013(2011)0000021013 
[4] Dunlap, G., \& Fox, L. (1999). Supporting families with young children with autism. Infants and Young Children, 12(2), 48-54.

[5] Dillenburger, K., Keenan, M., Gallager, S., \& McElhinney, M. (2002). Autism: Intervention and parent empowerment. Child Care in Practice, 8, 216-219.

[6] Lai, M., Lombardo, M. V., \& Baron-Cohen, S. (2014). Autism. The Lancet, 383(9920), 896-910. doi:http://dx.doi.org/10.1016/S0140-6736(13)61539-1

[7] Beurkens, N. M., Hobson, J. A., \& Hobson, R. P. (2013). Autism severity and qualities of parent-child relations. Journal of Autism and Developmental Disorders, 43(1), 168-78. doi:http://dx.doi.org/10.1007/s10803-012$1562-4$

[8] Solomon, A. H., \& Chung, B. (2012). Understanding autism: How family therapists can support

[9] parents of children with autism spectrum disorders. Family Process, 51(2), 250-64. Retrieved from http://search. . roquest.com/docview/1285243517?accountid=458

[10] Benson, P. R., \& Karlof, K. L. (2009). Anger, stress proliferation, and depressed mood among parents of children with ASD: A longitudinal replication. Journal of Autism and Developmental Disorders, 39(2), 350-62. doi:http://dx.doi.org/10.1007/s10803-008-0632-0

[11] Cashin, A. (2004). Painting the vortex: the existential structure of the experience of parenting a child with autism. International Forum of Psychoanalysis, 13, 164-174.

[12] Hastings, R. P., Kovshoff, H., Ward, N. J., Espinosa, F., Brown, T., \& Remington, B. (2005). Systems analysis of stress and positive perceptions in mothers and fathers of pre-school children with autism. Journal of Autism and Developmental Disorders, 35(5), 635-644.

[13] Gray, D. E. (2002). Ten years on: A longitudinal study of families of children with autism. Journal of Intellectual and Developmental Disabilty, 27(3), 215-222.

[14] Hastings, R. P., \& Beck, A. (2004). Practitioner review: Stress intervention for parents of children with intellectual disabilities. Journal of Child Psychology and Psychiatry, 45(8), 1338-1349.

[15] M.L. Matson et al. / Research in Autism Spectrum Disorders 3 (2009) 868-875

[16] Singh, N. N., Lancioni, G. E., Winston, A.S., Fisher, B. C., Wahler, R. G., McAleavey, K., et al.

[17] (2006). Mindful parenting decreases aggression, noncompliance, and self-injury in children with

[18] autism. Journal of Emotional and Behavioral Disorders, 14(3), 169-177. 